\title{
AVALIAÇÃO DA VAZÃO INDISPONIBILIZADA POR USINAS HIDRELÉTRICAS EM BACIAS HIDROGRÁFICAS E A COBRANÇA PELO USO DA ÁGUA NO SETOR ELÉTRICO
}

\author{
Ingrid Illich Müller ${ }^{1}$, Nivaldo Eduardo Rizzi ${ }^{2}$, Heinz Dieter Fill ${ }^{3}$ \\ ${ }^{1} E^{2}{ }^{a}$ Civil, Dr ${ }^{\mathrm{a}}$., LACTEC CEHPAR, Curitiba, PR, Brasil - ingrid@lactec.org.br \\ ${ }^{2}$ Eng. Florestal, Dr., Depto. de Engenharia e Tecnologia Florestal, UFPR, Curitiba, PR, Brasil - niva@ufpr.br \\ ${ }^{3}$ Eng. Mecânico, Dr., Depto. de Hidráulica e Saneamento, UFPR, Curitiba, PR, Brasil - fill@yahoo.com
}

Recebido para publicação: 02/12/2009 - Aceito para publicação: 16/08/2011

\begin{abstract}
Resumo
Este artigo tem por objetivo apresentar uma metodologia para avaliação da vazão indisponibilizada aos demais usuários de bacias hidrográficas quando da implantação de aproveitamentos hidrelétricos, visando subsidiar o aprimoramento do mecanismo de cobrança vigente para o setor hidrelétrico. Propõe-se a alteração desse mecanismo de cobrança, que é baseado na energia gerada, por uma metodologia que considere a alteração na disponibilidade hídrica causada pelas usinas e que ao mesmo tempo tenha fundamentação teórica e física. Propõe-se nesta pesquisa a adoção das vazões indisponibilizadas pelas usinas hidrelétricas para quantificar o uso da água na estrutura de cobrança. Para determinação dessas vazões, foram selecionados os modelos hidrológicos da curva de permanência e do déficit total de água. Os modelos foram aplicados às usinas hidrelétricas de Foz do Areia, Segredo, Salto Santiago e Salto Osório, situadas no rio Iguaçu, no estado do Paraná. Os resultados obtidos indicam que as usinas com capacidade de regularização são mais oneradas que as usinas a fio d'água, e que as vazões indisponibilizadas obtidas pelo método do déficit são sempre superiores às obtidas pela curva de permanência, porém bastante adequadas quando se considera o cenário da vazão máxima outorgável.

Palavras-chave: Cobrança pelo uso da água; usinas hidrelétricas; vazão indisponibilizada; curva de permanência; déficit de água.
\end{abstract}

\begin{abstract}
Assessment of unavailable water flow from hydroelectric dams in river basins and the water use charge mechanism for the hydroelectric sector. The main purpose of this article is to present a methodology to evaluate unavailable flows from hydroelectric power plants in river basins, in order to improve the water use charge mechanism for the hydroelectric sector. This research propose a change in the existing charging mechanism, which is based on the energy generated, to one that considers the changes in the water availability caused by power plants to other users in the river basin. The methodology proposes the use of unavailable flows to quantify the water use. Obtaining unavailable flows involved the use of duration curves and water deficit methods. The proposed methodology was applied to the Foz do Areia, Segredo, Salto Santiago, and Salto Osório hydroelectric power plants located on the Iguaçu River, Paraná State. The results indicate that power plants with storage capacity are more burdened than power plants without storage capacity, and that the unavailable water flows obtained by the deficit method are always greater than that obtained from the duration curve, but quite appropriate when considering the water permits scenario.
\end{abstract}

Keywords: Bulk water price; power dams; unavailability flows; duration curve; water deficit.

\section{INTRODUÇÃO}

A água era considerada, até recentemente, por boa parcela das sociedades do planeta, um recurso natural renovável e abundante, que poderia atender a todos os usos sem restrições. No entanto, a partir da segunda metade do século passado, o crescimento demográfico, o uso intensivo da água nos processos 
produtivos e a poluição gerada pelo conjunto de atividades humanas provocaram uma profunda reavaliação dos conceitos de disponibilidade e abundância desse recurso (CORDEIRO NETTO, 2004).

A evolução do quadro de escassez qualitativa e quantitativa do recurso água promoveu a mudança de conceitos na área ambiental. Novos paradigmas foram introduzidos, tentando unir visões de conservação e economia, culminando com a adoção, a partir da Conferência de Dublin em 1992, do conceito de "valor econômico da água". Nesse contexto, no Brasil, com a promulgação da Lei $\mathrm{n}^{\circ}$ 9.433/97, também conhecida por Lei das Águas, inicia-se uma nova fase para o gerenciamento dos recursos hídricos do país, fundamentada nos pressupostos da gestão integrada e participativa e baseada em instrumentos de gestão, entre os quais a cobrança pelo uso da água.

A cobrança pelo uso da água visa garantir a utilização eficiente do recurso água e o combate ao desperdício, garantindo que o uso desse recurso atenda aos princípios do desenvolvimento sustentável. Além de racionalizar o uso, a cobrança atua também como mecanismo de financiamento de programas e intervenções na bacia, além de dar suporte financeiro ao sistema de gestão de recursos hídricos. Entretanto, a implementação da cobrança, no contexto de gestão dos recursos hídricos, somente se justifica em bacias que apresentem escassez, problemas de qualidade ou conflitos de uso. Segundo Kelman (2000), "a cobrança só deve ser implementada em bacias hidrográficas em que o conflito pelo uso ou a degradação ambiental já sejam problemas reais ou estejam prestes a eclodir".

A atual cobrança pelo uso da água aplicada aos empreendimentos hidrelétricos está diretamente relacionada à compensação financeira. A compensação financeira ou participação nos resultados da exploração de recursos hídricos para fins de geração de energia elétrica e de outros recursos minerais no respectivo território, plataforma continental, mar territorial ou zona econômica exclusiva, é assegurada aos estados, ao Distrito Federal e aos municípios, bem como a órgãos da administração direta da União, pela Constituição Federal de 1988.

Este artigo apresenta uma metodologia para avaliação da vazão indisponibilizada pelas usinas hidrelétricas em bacias hidrográficas para compor a base de cálculo da cobrança pelo uso da água para o setor hidrelétrico brasileiro, à luz da legislação hídrica brasileira. A metodologia desenvolvida foi aplicada às usinas hidrelétricas de Foz do Areia, Segredo, Salto Santiago e Salto Osório, situadas no rio Iguaçu, no estado do Paraná.

\section{REVISÃO BIBLIOGRÁFICA}

Existem diversas metodologias econômicas e de valoração ambiental para determinação do valor da água, não existindo, porém, consenso sobre qual é a mais adequada. Os métodos diferem na forma de cálculo, na forma de implementação e na informação em que são baseados, conforme detalhado em Tavares et al. (1999).

Para Carrera-Fernandez e Garrido (2002), os modelos econômicos de formação dos preços da água, sob o ponto de vista do enquadramento teórico, podem ser classificados em dois grandes grupos: os modelos de otimização, que são derivados de um processo de otimização com postulados amplamente aceitos e fundamentados em algum ramo da teoria econômica; e os modelos $a d$ hoc, que são aqueles que não se enquadram na categoria anterior, ou seja, não são fruto de processos de otimização estabelecidos pela teoria econômica. Da mesma forma, os modelos de valoração ambiental são normalmente subdivididos em duas abordagens distintas. A primeira fundamenta-se nas relações físicas entre as causas e os efeitos da degradação ambiental, ou de sua melhora; a segunda abordagem estima a curva de demanda para um dado bem ou serviço ambiental, ou para um dado nível de qualidade ambiental a ser atingido ou mantido. Entretanto, a determinação do preço unitário da água depende, além de teorias econômicas e de valoração ambiental, de fatores regionais (objetivos da cobrança e condicionantes específicas da bacia hidrográfica) e do resultado de um processo político de negociação no âmbito do Conselho Nacional de Recursos Hídricos (CNRH) e do setor elétrico.

A utilização de teorias econômicas constitui-se em etapa importante não só para o alcance de objetivos estratégicos propostos com a implementação da cobrança como também para correção de eventuais distorções, tais como o ônus excessivo ou a subavaliação da água, que podem inviabilizar a implementação da cobrança pelo seu uso. A manipulação de dados e as negociações políticas podem produzir valores artificiais para a cobrança, como comprovado pela experiência francesa, em que o valor final da cobrança quase triplicou desde 1991 (PEREIRA, 2002). 
No Brasil, após a sanção da Lei $n^{0}$ 9.433/97, que instituiu a Política Nacional de Recursos Hídricos (PNRH) e criou o Sistema Nacional de Gerenciamento de Recursos Hídricos (SINGREH), a União, com o objetivo de agilizar a implementação da PNRH, definiu que a cobrança pelo uso da água referente às usinas hidrelétricas seria um percentual da compensação financeira paga pelas usinas.

A cobrança pelo uso da água, conforme definido pela Lei $n^{\circ} 9.433 / 97$, passou a vigorar para o setor elétrico a partir da publicação da Lei ${ }^{\circ}$ 9.984/00. Essa lei definiu que a compensação financeira pela utilização de recursos hídricos para fins de geração de energia elétrica paga pelos concessionários de energia elétrica passa de $6 \%$ para $6,75 \%$ do valor da energia produzida, sendo que os recursos correspondentes à parcela do $0,75 \%$ "constitui pagamento pelo uso de recursos hídricos" (BRASIL, 2004).

A compensação financeira de $6 \%$ pela "utilização dos recursos hídricos", conhecida por CFURH, instituída pela Lei $\mathrm{n}^{0} 7.990$, de 28 de dezembro de 1989, representa o pagamento pela exploração dos recursos hídricos para fins de geração de energia elétrica e deve ser paga pelos concessionários de serviço de energia elétrica aos estados, ao Distrito Federal e aos Municípios, em cujos territórios se localizarem instalações destinadas à produção de energia elétrica, ou que tenham áreas invadidas por águas dos respectivos reservatórios.

O valor da compensação financeira, considerando a edição das Leis $\mathrm{n}^{0}$ 7.990/89, 9.433/97 e 9.984/00, para cada usina hidrelétrica, é calculada pela equação (1):

$$
C F_{i}=6,75 \% \times E G_{i} \times T A R
$$

em que: $C F_{i}$ : é a compensação financeira a ser paga para o mês $i$ em cada usina hidrelétrica, em R\$;

$E G_{i}$ : é a energia gerada pela usina no mês $i$, em MWh;

$T A R$ : é a tarifa atualizada de referência, em $\mathrm{R} \$ \mathrm{MWh}$.

A fixação da TAR é feita pela Agência Nacional de Energia Elétrica (ANEEL), com base nos preços de venda da energia destinada ao suprimento das concessionárias de serviço público de distribuição de energia elétrica, excluindo-se os encargos setoriais vinculados à atividade de geração, tributos e empréstimos compulsórios, bem como os custos incorridos na transmissão de energia elétrica. Quanto ao recolhimento, cada concessionária realiza o cálculo da compensação financeira devida, informando à ANEEL, até o dia 20 do mês subsequente ao da geração, os montantes de energia gerada e os valores a serem recolhidos, individualizados por central geradora. A ANEEL fiscaliza a conformidade dos cálculos e dos valores recolhidos. A TAR definida para o ano de 2009 foi de R \$62,33/MWh.

O mecanismo de cobrança pelo uso dos recursos hídricos em vigor para o setor elétrico, apesar de apresentar pontos positivos, como a simplicidade da base de cálculo, o que possibilitou sua aplicação em curto prazo, não se integra perfeitamente às diretrizes do SINGREH, pois desconsidera alguns importantes fundamentos da PNRH. Um aspecto que merece ser destacado diz respeito à definição do valor a ser cobrado. Segundo a Lei $\mathrm{n}^{0}$ 9.433/97, devem ser considerados na cobrança o volume de água utilizado e seu regime de variação, enquanto que a cobrança nos moldes vigentes para o setor elétrico tem como referência apenas a quantidade de energia gerada. Isso pode ser relevante, dado que existem usinas que geram a mesma quantidade de energia utilizando vazões diferentes e provocando alterações distintas de regime do curso de água. Ou seja, não se considera o impacto gerado pelo empreendimento hidrelétrico sobre a disponibilidade hídrica da bacia hidrográfica.

Outro aspecto diz respeito à forma de implementação da cobrança para o setor hidrelétrico. Enquanto a legislação de recursos hídricos estabelece que cabe aos comitês de bacia, como elementos indutores do processo participativo, estabelecer os mecanismos de cobrança pelo uso de recursos hídricos e sugerir os valores a serem cobrados, bem como sugerir as eventuais alterações de rumo, a cobrança para o setor elétrico foi implementada de maneira unilateral, sob força da Lei $\mathrm{n}^{0} 9.984 / 00$, não permitindo aos comitês qualquer manifestação.

Por fim, ressalte-se que, apesar dos recursos advindos com a cobrança pelo uso da água para o setor elétrico terem se constituído ao longo dos últimos anos como principal fonte de financiamento do SINGREH, e da dificuldade política de se alterar o mecanismo atual de cobrança no curto prazo, especialmente devido ao risco do SINGREH sofrer um forte impacto no caso de mudanças significativas na arrecadação proveniente do setor hidrelétrico, é notório que, no médio prazo, a concepção e operacionalização desse instrumento precisam ser revistos à luz da legislação hídrica brasileira. 


\section{MATERIAL E MÉTODOS}

\section{Conceituação do modelo proposto para a cobrança pelo uso da água para setor hidrelétrico}

A metodologia proposta para a cobrança pelo uso da água segue a estrutura básica adotada nas bacias hidrográficas onde a cobrança encontra-se implementada, conforme expresso na equação (2):

Valor da Cobrança = Base de Cálculo x Preço Unitário x Coeficientes

Nessa estrutura de cobrança, a base de cálculo quantifica o volume de água utilizado; o preço unitário define o valor monetário da água segundo os objetivos pretendidos com a cobrança; e os coeficientes permitem diferenciar a cobrança em função de particularidades locais ou regionais.

A base de cálculo que quantifica o uso da água corresponde, neste estudo, à vazão indisponibilizada aos demais usuários da bacia hidrográfica, em função da existência ou implantação de usinas hidrelétricas na bacia. As vazões indisponibilizadas foram obtidas pela análise das séries temporais de vazões naturais e defluentes por intermédio das técnicas da curva de permanência (PINTO et al., 1976) e do déficit total de água (GOMIDE, 1983).

Os métodos da curva de permanência e do déficit total de água foram selecionados para quantificar o uso da água, dentre os diversos métodos hidrológicos existentes, por apresentarem, além da simplicidade conceitual, fundamentação teórica e física largamente aceita pela comunidade científica e técnica para representação da interferência causada pelos reservatórios nas bacias hidrográficas e também por estarem apoiados em dados disponíveis ou facilmente quantificáveis.

O preço unitário, que corresponde ao preço da unidade de água representativo do uso da água, e os coeficientes, que permitem a adaptação do mecanismo a objetivos específicos, diferenciar usuários e tipos de uso, não foram determinados neste estudo, em função de sua complexidade e por não serem o foco deste trabalho. Alternativamente, foi utilizado o fator de bacia, que corresponde, neste artigo, ao componente multiplicador das vazões indisponibilizadas, como indica a equação (3):

$$
\text { Valor da Cobrança = Vazões Indisponibilizadas x Fator de Bacia }
$$

O fator de bacia corresponde à média, na bacia, da relação entre os valores pagos pelo uso da água de acordo com a metodologia vigente e a vazão total indisponibilizada em cada usina, segundo os métodos propostos. Esse critério garante que o total arrecadado por bacia com a aplicação dos métodos propostos é semelhante à arrecadação atual com a metodologia vigente, preservando a arrecadação nas bacias enquanto se avalia a possibilidade de alteração da metodologia de cobrança pelo uso da água para o setor elétrico.

A metodologia proposta, dada pela equação (3), foi aplicada às usinas hidrelétricas de Foz do Areia, Segredo, Salto Santiago e Salto Osório, situadas no rio Iguaçu, no estado do Paraná. As principais características dessas usinas estão apresentadas na tabela 1.

Tabela 1. Principais características das usinas hidrelétricas do rio Iguaçu.

Table 1. Key attributes of Iguaçu River Power Plants.

\begin{tabular}{|c|c|c|c|c|}
\hline Usina Hidrelétrica & $\begin{array}{c}\text { Foz do } \\
\text { Areia }\end{array}$ & Segredo & $\begin{array}{c}\text { Salto } \\
\text { Santiago }\end{array}$ & Salto Osório \\
\hline Início da operação & $22 / 09 / 80$ & $26 / 09 / 92$ & $03 / 01 / 81$ & $14 / 10 / 75$ \\
\hline Latitude & $26^{0} 00^{\prime} 50^{\prime \prime}$ & $25^{\circ} 47^{\prime} 17^{\prime \prime}$ & $25^{0} 37^{\prime} 16^{\prime \prime}$ & $25^{0} 32^{\prime} 14^{\prime \prime}$ \\
\hline Longitude & $51^{0} 39^{\prime} 52^{\prime}$ & $52^{0} 06^{\prime} 51^{\prime \prime}$ & $52^{0} 36^{\prime} 32^{\prime}$ & $53^{0} 00^{\prime} 32^{\prime \prime}$ \\
\hline Área de drenagem $\left(\mathrm{km}^{2}\right)$ & 30.127 & 34.346 & 43.852 & 45.769 \\
\hline Vazão média de longo termo $(1931-2001)\left(\mathrm{m}^{3} / \mathrm{s}\right)$ & 654 & 750 & 995 & 1.042 \\
\hline Vazão média (1995-2001) (m³/s) & 915 & 1100 & 1149 & 1.512 \\
\hline Queda nominal líquida (m) & 135 & 110 & 102 & 68,4 \\
\hline Volume útil $\left(\mathrm{hm}^{3}\right)$ & $3.804,7$ & 383,7 & $4.112,9$ & 402,7 \\
\hline Número de máquinas & 4 & 4 & 4 & 6 \\
\hline Potência instalada (MW) & 1.676 & 1.260 & 1.420 & 1.050 \\
\hline Operadora & COPEL & COPEL & TRACTEBEL & TRACTEBEL \\
\hline
\end{tabular}

Obtenção de dados de simulação do modelo de cobrança proposto

Os dados necessários para aplicação da metodologia proposta, de acordo com a equação (3), são fundamentalmente as séries diárias de vazões naturais e defluentes das usinas hidrelétricas (Foz do Areia, 
Segredo, Salto Santiago e Salto Osório), para determinação das vazões indisponibilizadas, e os valores pagos por essas usinas, a título de compensação financeira, para cálculo do fator de bacia do rio Iguaçu. $\mathrm{O}$ período de dados utilizado foi de 1995 a 2001, que corresponde ao período comum de dados disponíveis de vazões e de compensação financeira.

A vazão natural, conforme usualmente empregada pelo setor elétrico, corresponde à vazão que ocorreria em uma seção do rio caso não houvesse ações antrópicas na bacia contribuinte, sendo obtida por um processo de reconstituição de vazões que considera a vazão no local e as informações relativas às ações antrópicas na bacia. A vazão defluente corresponde à vazão observada a jusante do aproveitamento em decorrência das regras operativas da usina, dada pela soma da vazão vertida (vazão liberada através de vertedouros de superfície e ou descarregadores de fundo) e da vazão turbinada (vazão que passa através das turbinas) (ONS, 2002; 2005).

As séries de vazões naturais e defluentes usadas neste artigo foram obtidas através do processo de reconstituição, a partir dos dados de vazões e precipitações medidas em estações fluviométricas e pluviométricas localizadas na bacia do rio Iguaçu, dos dados operativos das usinas e da incorporação das informações dos usos consuntivos e das perdas por evaporação. Maiores detalhes podem ser consultados em LACTEC (2003).

Para o cálculo do fator de bacia para o rio Iguaçu, foram considerados os valores pagos a título de compensação financeira pelo setor elétrico, no período de 1995 a 2001, conforme demonstrativos publicados pela ANEEL no site www.aneel.gov.br (ANEEL, 2007).

\section{Fator de bacia}

O fator de bacia corresponde à média dos valores obtidos em cada usina que compõe a bacia hidrográfica da relação entre os valores pagos pelo uso da água pela usina de acordo com a metodologia atual e a vazão total indisponibilizada pela usina segundo os métodos propostos. Ou seja, o fator de bacia corresponde à média na bacia da relação entre os valores pagos pelo uso da água de acordo com a metodologia atual $(0,75 \%$ da compensação financeira) e as vazões indisponibilizadas em cada usina segundo os métodos propostos (curva de permanência e do déficit total de água).

A adoção desse critério garante que o total arrecadado por bacia com a aplicação dos métodos propostos seja semelhante à arrecadação atual com a metodologia vigente, preservando a arrecadação nas bacias e garantindo a estabilidade do sistema de cobrança ora vigente.

Por fim, vale ressaltar que o objetivo central deste artigo é a apresentação de uma nova metodologia para cálculo das vazões indisponibilizadas. Os demais elementos que compõem a base de cálculo da cobrança pelo uso da água para o setor hidrelétrico brasileiro (preço unitário e coeficientes), devido à sua complexidade, devem ser fruto de novos estudos.

\section{Avaliação da vazão indisponibilizada pelo método da curva de permanência $\left(Q C P_{I N D}\right)$}

As curvas de permanência relacionam a vazão com a sua probabilidade de ocorrência ao longo do tempo, indicando a porcentagem de tempo que um determinado valor de vazão foi igualado ou ultrapassado durante o período de observação. São consideradas como procedimentos hidrológicos mais representativos para avaliar a disponibilidade hídrica de bacias por refletirem com grande propriedade o efeito regulador dos reservatórios nas bacias hidrográficas. As curvas de permanência representam as características hídricas de longo prazo das bacias, porém não representam a ocorrência das vazões em sua sequência natural. Não se sabe, por exemplo, se as menores vazões ocorreram em períodos consecutivos ou intermitentemente na série de registros, o que pode ser inadequado em determinados estudos (LINSLEY; FRANZINI, 1978).

Inicialmente foram obtidas as curvas de permanência anuais, construídas com dados de vazões diárias naturais e defluentes, com base na técnica empírica. O procedimento empírico empregado na construção de curvas de permanência pode ser assim explicitado: i) ordenam-se as $N$ vazões $Q$ disponíveis em ordem decrescente; ii) atribui-se a cada vazão ordenada $Q_{i}$ a sua respectiva ordem de classificação $i$; iii) associa-se a cada vazão ordenada $Q_{i}$ a sua respectiva frequência ou probabilidade empírica de ser igualada ou superada $P_{i}\left(Q>Q_{i}\right)$, a qual pode ser estimada pela razão $(i /(N+1))$.

A seguir, foram obtidas as vazões indisponibilizadas pela técnica da curva de permanência $\left(Q C P_{I N D}\right)$ no período considerado, dadas pela diferença entre a vazão defluente $\left(Q_{D E F}\right)$ e a vazão natural 
$\left(Q_{N A T}\right)$, ambas extraídas das respectivas curvas de permanência, para uma permanência x \% selecionada, em $\mathrm{m}^{3} / \mathrm{s}$, como mostra a equação (4). Para apresentação dos resultados, foi adotada a permanência de $95 \%$, por ser essa permanência muito utilizada, em vários estados brasileiros, na definição da vazão de outorga.

$$
\left(Q C P_{I N D}\right)=\left(Q_{D E F}-Q_{N A T}\right)_{X \%}
$$

\section{Avaliação da vazão indisponibilizada pelo método do déficit total de água $\left(Q D T A_{I N D}\right)$}

O conceito do déficit total de água, adotado neste estudo, deriva da teoria dos déficits acumulados usado no dimensionamento de reservatórios. O déficit acumulado origina-se da curva de diferenças totalizadas, que, por sua vez, deriva da curva de massa das vazões, também conhecida como diagrama de Rippl (PINTO et al., 1976). A curva de massa representa a integral do hidrograma de vazões, correspondendo aos volumes totais afluentes ao reservatório em função do tempo, enquanto que a curva de diferenças totalizadas representa os volumes acumulados obtidos pelas diferenças entre as vazões afluentes e a respectiva vazão média. Se, na curva de diferenças totalizadas, consideram-se os valores acumulados das diferenças entre as vazões observadas e a vazão a ser regularizada, fazendo essas diferenças iguais a zero quando forem positivas, tem-se a curva dos déficits acumulados (GOMIDE, 1983). Neste estudo, o "déficit total de água" é definido como sendo a somatória acumulada total do período, das diferenças entre vazões defluentes e vazões naturais, ou entre vazões defluentes e a vazão máxima outorgável.

Para determinação das vazões indisponibilizadas pelo método do déficit total de água ( $\left.Q D T A_{I N D}\right)$ aos demais usuários da bacia hidrográfica, foram considerados dois cenários distintos: cenário 1, que corresponde a uma situação ideal, pouco provável na prática; e cenário 2, que representa a situação real do uso de água no contexto das bacias hidrográficas brasileiras.

No cenário 1, as vazões indisponibilizadas são função das vazões defluentes e das vazões naturais. Nesse cenário, o usuário situado a jusante da usina hidrelétrica percebe a influência da usina sempre que a vazão que passa no local (vazão defluente) for menor que a vazão que passaria (vazão natural) na condição de ausência da usina.

No cenário 2, as vazões indisponibilizadas são função das vazões defluentes e da vazão máxima outorgável, uma vez que, em condições reais, cada usuário poderá alocar, no máximo, para aquele trecho de rio, a vazão máxima outorgável. Neste artigo foi adotada a vazão máxima outorgável igual à vazão com $95 \%$ de permanência $\left(\mathrm{Q}_{95 \%}\right)$, pelo fato de ela ser usualmente empregada para esse fim em diversos estados brasileiros. Desse modo, tem-se que a $Q D T A_{I N D}$ é dada por:

- Cenário 1: corresponde à soma acumulada, no período de 1995 a 2001, das diferenças parciais entre as vazões defluentes diárias $\left(Q_{D E F}\right)$ e as vazões diárias naturais $\left(Q_{N A T}\right)$, para todo $Q_{D E F}<Q_{N A T}$, e igual a zero para todo $Q_{D E F}>Q_{N A T}$, conforme a equação (5):

$$
Q D T A_{I N D}=\sum_{i=1}^{N}\left(Q_{D E F_{i}}-Q_{N A T_{i}}\right)
$$

- Cenário 2: corresponde à soma acumulada, no período de 1995 a 2001, das diferenças parciais entre as vazões defluentes diárias $\left(Q_{D E F}\right)$ e a vazão máxima outorgável $\left(Q_{95 \%}\right)$, para todo $Q_{D E F}<Q_{95 \%}$, e igual a zero para todo $Q_{D E F}>Q_{95 \%}$, conforme a equação (6):

$$
Q D T A_{I N D}=\sum_{i=1}^{N}\left(Q_{D E F_{i}}-Q_{95 \%}\right)
$$

Por fim, para obtenção dos valores da cobrança, após a determinação das vazões indisponibilizadas pelos métodos apresentados e fazendo uso do fator de bacia, aplica-se a equação (3). 


\section{RESULTADOS E DISCUSSÃO}

\section{Fator de bacia}

No que concerne à adoção do fator de bacia como componente multiplicador da vazão indisponibilizada, cabe esclarecer que esse procedimento teve por finalidade exclusiva permitir a apresentação de valores finais de cobrança, visto que o objetivo principal do artigo é a determinação das vazões indisponibilizadas. O uso de teorias econômicas ou de valoração ambiental para determinação do preço unitário e coeficientes, devido à sua complexidade, deve ser fruto de novos estudos e não faz parte do escopo pretendido para este artigo.

A tabela 2 apresenta os fatores de bacia calculados para o rio Iguaçu para os métodos da curva de permanência e do déficit total de água para os cenários 1 e 2 .

Tabela 2. Fator de bacia para a bacia do rio Iguaçu.

Table2. Basin factor for the Iguaçu basin.

\begin{tabular}{lc}
\hline Método & Fator de bacia $\left(\mathbf{R} \$ /\left(\mathbf{m}^{\mathbf{3}} / \mathbf{s}\right)\right)$ \\
\hline Curva de permanência & $36.706,29$ \\
Déficit total de água - Cenário 1 & 14,09 \\
Déficit total de água - Cenário 2 & 1037,64 \\
\hline
\end{tabular}

Com relação aos fatores de bacia obtidos para o rio Iguaçu, destaca-se que eles diferem significativamente de acordo com o método avaliado. Essas diferenças eram esperadas e são função da especificidade e das características distintas dos métodos empregados.

Entretanto, cabe enfatizar que o uso do fator de bacia se mostrou bastante adequado, pois, ao garantir a manutenção da arrecadação total na bacia com a implementação da metodologia proposta, permite que ela seja avaliada de forma equilibrada tanto pelos órgãos gestores como pelos concessionários pagantes.

Por fim, apesar da discussão de o preço justo a ser cobrado pelo uso da água não ser o foco deste artigo, uma análise dos resultados obtidos indica que o valor $\mathrm{do}^{3} / \mathrm{s}$ de água pago pelo setor elétrico atualmente é bastante superior ao valor pago pelos outros usuários, independentemente do valor que seja dado aos coeficientes. Ademais, vale lembrar que a arrecadação na sua forma atual não retorna às bacias onde foi originada, com o agravante de que grande parte do valor (em média mais que $70 \%$ ) vem sendo sistematicamente contingenciado, causando preocupação e descontentamento (SUGAI, 2008).

\section{Vazões indisponibilizadas e valores de cobrança pelo método da curva de permanência}

As vazões indisponibilizadas e os correspondentes valores a serem cobrados obtidos pela aplicação do método da curva de permanência aos dados das usinas hidrelétricas do rio Iguaçu estão apresentados na tabela 3 .

Esta tabela mostra, para o período de 1995 a 2001, anualmente e para o período total de dados, a vazão natural para 95\% de permanência (coluna 3), a vazão defluente para 95\% de permanência (coluna 4), a vazão indisponibilizada correspondente (coluna 5), os valores de cobrança propostos a partir de curvas de permanência (coluna 6) e os valores cobrados atualmente $(0,75 \%$ da compensação financeira) (coluna 7).

Pela análise das vazões naturais e defluentes obtidas pelo método da curva de permanência, expressos na tabela 3, quando se considera o período total de dados utilizado, fica evidente que todas as usinas, à exceção da usina de Foz do Areia, contribuíram para a melhoria da disponibilidade hídrica na bacia, não indisponibilizando água no período de 1995 a 2001.

Da mesma forma, ao se avaliarem as vazões naturais e defluentes obtidas pelo método da curva de permanência anual, expressos na tabela 3, nota-se que, excetuando a usina de Foz do Areia, apenas em 1 ou 2 anos do período estudado houve indisponibilização de vazões. Ou seja, com exceção da usina de Foz de Areia, pode-se dizer que as usinas do rio Iguaçu não indisponibilizaram água para períodos superiores a 2 anos.

Este resultado pode ser facilmente explicado pelo fato de a usina de Foz de Areia ser uma usina de acumulação. Usinas com função de reservação têm a finalidade precípua de armazenar água indisponibilizar água - em determinados períodos, para liberá-los posteriormente, de acordo com as regras de operação definidas para a usina. Interessante notar que os resultados obtidos com as curvas de 
permanência anuais indicaram que apenas as usinas de Salto Osório e Foz do Areia, ambas usinas de reservação, indisponibilizaram água para período superior a 1 ano, corroborando a informação de que esse tipo de usinas - usinas de armazenamento - indisponibilizam água em determinados períodos.

Tabela 3. Vazões naturais $\left(\mathrm{Q}_{\mathrm{NAT} 95 \%}\right)$ e defluentes $\left(\mathrm{Q}_{\mathrm{DEF95} \%}\right)$ com $95 \%$ de permanência, vazão indisponibilizada $\left(\mathrm{QCP}_{\mathrm{IND}}\right)$ e as cobranças atual e proposta pelo método da curva de permanência, para as usinas hidrelétricas do rio Iguaçu.

Table 3. Natural ( $\left.\mathrm{Q}_{\mathrm{NAT} 95 \%}\right)$ and release $\left(\mathrm{Q}_{\mathrm{DEF} 95 \%}\right)$ flows, with $95 \%$ duration, unavailable water flows $\left(\mathrm{QCP}_{\mathrm{IND}}\right)$ and the charges to Iguaçu River power plants using current method and the proposed duration curve method.

\begin{tabular}{|c|c|c|c|c|c|c|}
\hline Usina hidrelétrica & Período & $\begin{array}{c}Q_{\text {NAT95\% }} \\
\left(\mathrm{m}^{3} / \mathbf{s}\right)\end{array}$ & $\begin{array}{c}\text { QDEF95\% }_{\text {DE }} \\
\left(\mathrm{m}^{3} / \mathrm{s}\right)\end{array}$ & $\begin{array}{c}\mathbf{Q C P}_{\text {IND }} \\
\left(\mathrm{m}^{3} / \mathrm{s}\right)\end{array}$ & $\begin{array}{l}\text { Cobrança } \\
\text { proposta } \\
(\mathrm{R} \$ / \mathbf{a n o})\end{array}$ & $\begin{array}{c}\text { Cobrança atual } \\
(\mathbf{0 , 7 5 \% )} \\
(\mathbf{R} \$ / \mathbf{a n o})\end{array}$ \\
\hline \multirow[t]{8}{*}{ Foz do Areia } & 1995 & 141,69 & 110,30 & 31,39 & $1.152 .210,44$ & $615.016,99$ \\
\hline & 1996 & 201,18 & 269,70 & 0,00 & 0,00 & $1.093 .328,16$ \\
\hline & 1997 & 180,11 & 177,90 & 2,21 & $81.120,90$ & $947.000,20$ \\
\hline & 1998 & 363,84 & 326,40 & 37,44 & $1.374 .283,50$ & $1.158 .629,70$ \\
\hline & 1999 & 212,34 & 121,30 & 91,04 & $3.341 .740,64$ & $912.056,61$ \\
\hline & 2000 & 153,60 & 5,99 & 147,61 & $5.418 .215,47$ & $717.671,62$ \\
\hline & 2001 & 373,22 & 141,30 & 231,92 & $8.512 .922,78$ & $1.672 .491,18$ \\
\hline & $1995-2001$ & 179,75 & 122,47 & 57,28 & $2.102 .536,29$ & $7.116 .194,46$ \\
\hline \multirow[t]{8}{*}{ Segredo } & 1995 & 182,47 & 244,20 & 0,00 & 0,00 & $563.226,04$ \\
\hline & 1996 & 247,19 & 413,90 & 0,00 & 0,00 & $1.009 .312,77$ \\
\hline & 1997 & 223,01 & 421,65 & 0,00 & 0,00 & $961.290,64$ \\
\hline & 1998 & 443,73 & 594,30 & 0,00 & 0,00 & $1.083 .413,03$ \\
\hline & 1999 & 275,36 & 319,10 & 0,00 & 0,00 & $947.668,94$ \\
\hline & 2000 & 217,79 & 186,85 & 30,94 & $1.135 .692,61$ & $847.032,33$ \\
\hline & 2001 & 456,93 & 548,50 & 0,00 & 0,00 & $1.666 .235,26$ \\
\hline & $1995-2001$ & 240,46 & 316,66 & 0,00 & 0,00 & $7.078 .179,00$ \\
\hline \multirow[t]{8}{*}{ Salto Santiago } & 1995 & 249,34 & 385,10 & 0,00 & 0,00 & $778.128,01$ \\
\hline & 1996 & 327,52 & 481,80 & 0,00 & 0,00 & $1.198 .386,02$ \\
\hline & 1997 & 352,93 & 532,70 & 0,00 & 0,00 & $1.251 .102,47$ \\
\hline & 1998 & 588,20 & 760,39 & 0,00 & 0,00 & $1.219 .524,05$ \\
\hline & 1999 & 336,98 & 577,08 & 0,00 & 0,00 & $1.181 .123,33$ \\
\hline & 2000 & 311,96 & 323,94 & 0,00 & 0,00 & $837.650,49$ \\
\hline & 2001 & 598,41 & 557,98 & 40,43 & $1.484 .035,30$ & $2.008 .123,86$ \\
\hline & $1995-2001$ & 330,71 & 429,31 & 0,00 & 0,00 & $8.474 .038,23$ \\
\hline \multirow{8}{*}{$\begin{array}{l}\text { Salto } \\
\text { Osório }\end{array}$} & 1995 & 265,43 & 447,42 & 0,00 & 0,00 & $543.919,11$ \\
\hline & 1996 & 342,60 & 518,65 & 0,00 & 0,00 & $820.786,43$ \\
\hline & 1997 & 375,18 & 621,87 & 0,00 & 0,00 & $851.284,98$ \\
\hline & 1998 & 614,56 & 785,04 & 0,00 & 0,00 & $942.636,48$ \\
\hline & 1999 & 343,32 & 541,17 & 0,00 & 0,00 & $790.773,37$ \\
\hline & 2000 & 330,93 & 256,79 & 74,14 & $2.721 .404,34$ & $648.671,46$ \\
\hline & 2001 & 627,02 & 534,60 & 92,42 & $3.392 .395,32$ & $1.347 .538,29$ \\
\hline & $1995-2001$ & 346,37 & 456,38 & 0,00 & 0,00 & $5.945 .610,12$ \\
\hline
\end{tabular}

Vazões indisponibilizadas e valores de cobrança pelo método do déficit total de água

As vazões indisponibilizadas e os correspondentes valores a serem cobrados obtidos pela aplicação do método do déficit total de água aos dados das usinas hidrelétricas do rio Iguaçu estão apresentados na tabela 4.

Essa tabela apresenta, para o período 1995 a 2001, para os cenários 1 e 2, a vazão indisponibilizada anualmente pelos métodos do déficit total de água (colunas 4 e 7), os respectivos valores a serem cobrados (colunas 5 e 8$)$ e os valores cobrados atualmente $(0,75 \%$ da compensação financeira) (coluna 9). 
Analisando os resultados da tabela 4, nota-se que as vazões indisponibilizadas pelo método do déficit total de água no cenário 1 são sempre superiores às vazões do cenário 2.

Esse resultado se justifica pela diferença significativa entre os valores das vazões naturais e das vazões $\mathrm{Q}_{95 \%}$, usadas nos cenários 1 e 2, respectivamente. As vazões naturais e as vazões $\mathrm{Q}_{95 \%}$ são conceitualmente diferentes, visto que as vazões naturais são aquelas que ocorrem normalmente nos rios, ao passo que as vazões $\mathrm{Q}_{95 \%}$ têm uma probabilidade de ocorrência associada.

Da mesma forma, quando analisamos os resultados obtidos para as vazões indisponibilizadas do cenário 1 (tabela 4), tem-se que elas são sempre superiores às vazões indisponibilizadas obtidas pelo método da curva de permanência (tabela 3 ).

Esse resultado está associado às características próprias da formulação dos métodos. Enquanto que o método da curva de permanência representa as características de longo prazo das bacias hidrográficas, o método do déficit total de água representa os balanços entre as entradas e saídas de vazão em cada unidade de tempo, definindo os volumes indisponibilizados para cada período de tempo analisado.

Tabela 4. Vazão indisponibilizada anual pelo método do déficit total de água (QDTA $\left.{ }_{\text {IND }}\right)$ para os cenários 1 e 2, e as cobranças proposta e atual para as usinas hidrelétricas do rio Iguaçu.

Table 4. Unavailable water flows estimated by the total deficit method (QDTA $\mathrm{IND}_{\mathrm{IND}}$ ) for scenarios 1 and 2, and the charges to Iguaçu River power plants using current and proposed methods.

\begin{tabular}{|c|c|c|c|c|c|c|c|c|}
\hline & Ano & & $\begin{array}{c}\text { QDTA }_{\text {IND }} \\
\left(\mathbf{m}^{3} / \mathbf{s}\right)\end{array}$ & $\begin{array}{c}\text { Cobrança } \\
\text { proposta } \\
\text { (R\$/ano } \\
\end{array}$ & & $\begin{array}{c}\text { QDTA }_{\text {IND }} \\
\left(\mathbf{m}^{3} / \mathbf{s}\right)\end{array}$ & $\begin{array}{c}\text { Cobrança } \\
\text { proposta } \\
(\mathrm{R} \$ / \mathbf{a n o}) \\
\end{array}$ & $\begin{array}{c}\text { Cobrança } \\
\text { atual }(0,75 \%) \\
(\mathbf{R} \$ / \mathbf{a n o}) \\
\end{array}$ \\
\hline \multirow{7}{*}{ 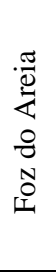 } & 1995 & \multirow{7}{*}{ 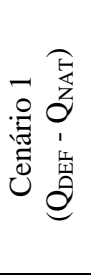 } & $54.514,60$ & $767.903,56$ & \multirow{7}{*}{ 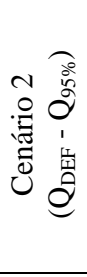 } & $2.712,85$ & $2.814 .975,24$ & $615.016,99$ \\
\hline & 1996 & & $49.045,32$ & $690.862,19$ & & 506,95 & $526.034,13$ & $1.093 .328,16$ \\
\hline & 1997 & & $49.301,03$ & $694.464,17$ & & $1.028,70$ & $1.067 .425,41$ & $947.000,20$ \\
\hline & 1998 & & $54.167,19$ & $763.009,87$ & & 355,75 & $369.142,21$ & $1.158 .629,70$ \\
\hline & 1999 & & $55.793,22$ & $785.914,46$ & & $2.313,85$ & $2.400 .954,88$ & $912.056,61$ \\
\hline & 2000 & & $69.157,35$ & $974.164,26$ & & $8.900,58$ & $9.235 .642,33$ & $717.671,62$ \\
\hline & 2001 & & $57.847,04$ & $814.844,97$ & & $1.963,10$ & $2.037 .000,90$ & $1.672 .491,18$ \\
\hline \multirow{7}{*}{ 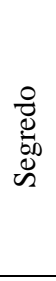 } & 1995 & \multirow{7}{*}{ 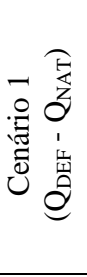 } & $58.324,64$ & $821.572,54$ & \multirow{7}{*}{ 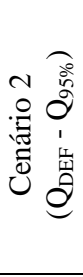 } & 824,64 & $855.683,57$ & $563.226,04$ \\
\hline & 1996 & & $47.984,32$ & $675.916,73$ & & 29,48 & $30.589,77$ & $1.009 .312,77$ \\
\hline & 1997 & & $39.275,37$ & $553.240,72$ & & 0,00 & 0,00 & $961.290,64$ \\
\hline & 1998 & & $46.560,35$ & $655.858,40$ & & 0,00 & 0,00 & $1.083 .413,03$ \\
\hline & 1999 & & $46.966,37$ & $661.577,68$ & & 550,12 & $570.829,27$ & $947.668,94$ \\
\hline & 2000 & & $54.877,28$ & $773.012,34$ & & $2.653,32$ & $2.753 .204,23$ & $847.032,33$ \\
\hline & 2001 & & $42.663,02$ & $600.959,83$ & & 0,00 & 0,00 & $1.666 .235,26$ \\
\hline \multirow{7}{*}{ 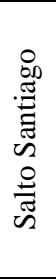 } & 1995 & \multirow{7}{*}{ 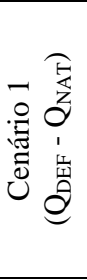 } & $97.016,29$ & $1.366 .590,86$ & \multirow{7}{*}{ 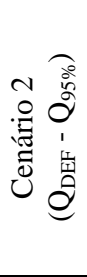 } & 522,39 & $542.055,37$ & $778.128,01$ \\
\hline & 1996 & & $97.602,27$ & $1.374 .845,10$ & & 304,28 & $315.734,62$ & $1.198 .386,02$ \\
\hline & 1997 & & $89.217,44$ & $1.256 .734,70$ & & 0,00 & 0,00 & $1.251 .102,47$ \\
\hline & 1998 & & $80.524,65$ & $1.134 .286,32$ & & 0,00 & 0,00 & $1.219 .524,05$ \\
\hline & 1999 & & $77.898,86$ & $1.097 .298,92$ & & 12,11 & $12.565,88$ & $1.181 .123,33$ \\
\hline & 2000 & & $112.780,38$ & $1.588 .646,99$ & & 497,60 & $516.332,15$ & $837.650,49$ \\
\hline & 2001 & & $86.119,91$ & $1.213 .102,28$ & & 377,15 & $391.347,81$ & $2.008 .123,86$ \\
\hline \multirow{7}{*}{ 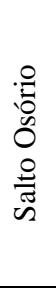 } & 1995 & \multirow{7}{*}{ 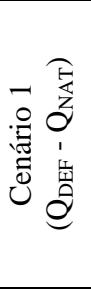 } & $97.950,75$ & $1.379 .753,85$ & \multirow{7}{*}{ 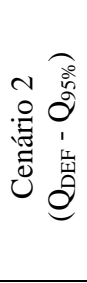 } & 215,97 & $224.100,19$ & $543.919,11$ \\
\hline & 1996 & & $97.582,61$ & $1.374 .568,16$ & & 510,23 & $529.437,61$ & $820.786,43$ \\
\hline & 1997 & & $92.381,16$ & $1.301 .299,50$ & & 87,81 & $91.115,61$ & $851.284,98$ \\
\hline & 1998 & & $91.604,09$ & $1.290 .353,53$ & & 58,94 & $61.158,80$ & $942.636,48$ \\
\hline & 1999 & & $78.361,34$ & $1.103 .813,51$ & & 0,00 & 0,00 & $790.773,37$ \\
\hline & 2000 & & $115.949,49$ & $1.633 .287,71$ & & $2.916,61$ & $3.026 .405,78$ & $648.671,46$ \\
\hline & 2001 & & $89.888,70$ & $1.266 .190,21$ & & 233,54 & $242.331,61$ & $1.347 .538,29$ \\
\hline
\end{tabular}

Tabelas-síntese dos resultados

O resumo dos resultados obtidos para as usinas hidrelétricas do rio Iguaçu está apresentado nas tabelas 5 e 6 . A tabela 5 apresenta as vazões indisponibilizadas acumuladas no período 1995 a 2001, pelos 
métodos da curva de permanência e do déficit total de água, e a tabela 6 apresenta os valores cobrados segundo a metodologia atual e os valores que seriam cobrados pelos métodos propostos da curva de permanência e do déficit total de água, para o período 1995 a 2001.

Tabela 5. Vazão indisponibilizada no período 1995 a 2001, para as usinas hidrelétricas do rio Iguaçu, obtidas pelos métodos da curva de permanência e do déficit total de água.

Table 5. Unavailable water flows estimated for the period between 1995 and 2001, for the Iguaçu River power plants, using the duration curve method and the total deficit method.

\begin{tabular}{lccc}
\hline \multirow{2}{*}{ Usina hidrelétrica } & \multicolumn{3}{c}{ Vazão indisponibilizada $\left(\mathbf{m}^{\mathbf{3}} / \mathbf{s}\right)$ - Período 1995 a 2001 } \\
\cline { 2 - 4 } & \multirow{2}{*}{ Curva de permanência } & \multicolumn{2}{c}{ Déficit total de água } \\
\cline { 2 - 4 } & & $\mathbf{Q}_{\mathrm{DEF}}-\mathbf{Q}_{\mathbf{N A T}}$ & $\mathbf{Q}_{\mathbf{D E F}}-\mathbf{Q}_{\mathbf{9 5} \%}$ \\
\hline Foz do Areia & 542 & 389.826 & 17.782 \\
Segredo & 31 & 336.651 & 4.058 \\
Salto Santiago & 40 & 641.160 & 1.714 \\
Salto Osório & 167 & 663.718 & 4.023 \\
\hline Total & 780 & 2.262 .167 & 27.576 \\
\hline
\end{tabular}

Tabela 6. Valores pagos pelas usinas hidrelétricas do rio Iguaçu e os valores propostos calculados pelos métodos da curva de permanência e do déficit total de água, no período 1995 a 2001.

Table 6. Charges to Iguaçu River power plants, using current method and proposed methods (duration curve and total deficit) for the period between 1995 and 2001.

\begin{tabular}{|c|c|c|c|c|}
\hline \multirow{3}{*}{$\begin{array}{l}\text { Usina } \\
\text { hidrelétrica }\end{array}$} & \multirow{3}{*}{$\begin{array}{c}\text { Cobrança atual } \\
(0,75 \%) \mathrm{R} \$ \text { /ano) }\end{array}$} & \multicolumn{3}{|c|}{ Cobrança proposta (R\$) (período 1995 a 2001) } \\
\hline & & \multirow{2}{*}{$\begin{array}{c}\text { Curva de } \\
\text { permanência }\end{array}$} & \multicolumn{2}{|c|}{ Déficit total de água } \\
\hline & & & $Q_{\text {DEF }}-Q_{\text {NAT }}$ & $Q_{\text {DEF }}-Q_{95 \%}$ \\
\hline Foz do Areia & 7.116 .194 & 19.880 .494 & 5.491 .163 & 18.451 .175 \\
\hline Segredo & 7.078 .179 & 1.135 .693 & 4.742 .138 & 4.210 .307 \\
\hline Salto Santiago & 8.474 .038 & 1.484 .035 & 9.031 .505 & 1.778 .036 \\
\hline Salto Osório & 5.945 .610 & 6.113 .800 & 9.349 .266 & 4.174 .550 \\
\hline Total & 28.614 .022 & 28.614 .021 & 28.614 .073 & 28.614 .067 \\
\hline
\end{tabular}

Analisando os resultados das vazões indisponibilizadas obtidos pelo método da curva de permanência e pelo método do déficit total de água, expressos na tabela 5, nota-se que as vazões geradas pelo método do déficit são sempre superiores às obtidas pelo método da curva de permanência.

Esse resultado é condizente com a teoria intrínseca de ambos os métodos: no método do déficit são procedidas somas parciais de períodos em que as vazões defluentes são menores que as vazões naturais (cenário 1) ou menores que a vazão máxima outorgável $\mathrm{Q}_{95 \%}$ (cenário 2), desconsiderando sempre os períodos em que ocorrem armazenamentos; enquanto as curvas de permanência têm por característica principal refletir o estado hídrico de longo de prazo das bacias hidrográficas.

Analisando os resultados dos valores da cobrança apresentados na tabela 6, os quais são diretamente proporcionais às vazões indisponibilizadas, tem-se que o valor a ser cobrado obtido quando se aplica o método do déficit total de água no cenário 1 é sempre superior aos valores a serem cobrados gerados pelo método da curva de permanência e pelo método do déficit total de água no cenário 2.

Entre os métodos avaliados, considerando os resultados obtidos e os conceitos físicos relacionados, registra-se a superioridade do método do déficit total de água no cálculo das vazões indisponibilizadas, quando comparado ao método da curva de permanência. A curva de permanência não evidencia os períodos críticos de disponibilidade hídrica, uma vez que não considera a temporalidade da ocorrência das vazões. Como a ordem cronológica de ocorrência das vazões é importante para que os pagamentos estejam vinculados com a disponibilidade hídrica na bacia em cada unidade do tempo, o método do déficit total de água é mais indicado.

Por fim, cabe ressaltar que o método do déficit total de água tem origem no conceito usado no dimensionamento de reservatórios, o que lhe imprime a noção de "tamanho", que, rebatido para este estudo, se traduz em "quantidade" de água indisponibilizada. Esse método se aproxima ainda mais da 
situação real de uso da água no contexto das bacias hidrográficas brasileiras quando aplicado com a vazão máxima outorgável (cenário 2).

\section{CONSIDERAÇÕES FINAIS}

A cobrança pelo uso da água que incide atualmente sobre o setor hidrelétrico caracteriza-se por apresentar uma base de cálculo distinta se comparada aos mecanismos de cobrança utilizados para os demais usuários, tendo como referência apenas a energia gerada em cada usina hidrelétrica. É indiscutível que a energia gerada não reflete perfeitamente o uso da água, uma vez que usinas distintas podem gerar a mesma quantidade de energia utilizando vazões diferentes. Essas usinas, nos moldes vigentes para o setor elétrico, apesar de provocarem alterações diferenciadas nos regimes fluviais, pagam o mesmo valor.

Visando aperfeiçoar o modelo de cobrança vigente, desenvolveu-se uma metodologia de cobrança pelo uso da água capaz de refletir a influência das usinas hidrelétricas sobre a disponibilidade hídrica das bacias hidrográficas, fundamentada em aspectos técnicos e conceituais amplamente utilizados pela comunidade científica e com respaldo na legislação de recursos hídricos brasileira. Essa metodologia, baseada nas técnicas da curva de permanência e do déficit total de água, teve por objetivo primordial a determinação das vazões indisponibilizadas pelas usinas hidrelétricas aos demais usuários da bacia hidrográfica.

A metodologia desenvolvida foi aplicada às usinas hidrelétricas de Foz do Areia, Segredo, Salto Santiago e Salto Osório, situadas no rio Iguaçu, no estado do Paraná.

No desenvolvimento da metodologia, foram utilizados dados hidrológicos disponibilizados pelo Operador Nacional do Sistema (ONS) e dados da compensação financeira pagos em cada usina hidrelétrica publicados pela ANEEL.

O mérito da metodologia desenvolvida reside em três pontos fundamentais:

(i) se baseia nos métodos da curva de permanência e déficit total de água, reconhecidas pela comunidade técnica e científica;

(ii) atende a legislação de recursos hídricos vigente no país, pois parte do pressuposto de que "cada usuário deve pagar pela quantidade de água indisponibilizada na bacia"; e

(iii) faz uso de dados disponíveis em todas as usinas do país, fator este importante quando se pretende tornar operacional uma determinada metodologia.

As principais conclusões obtidas neste estudo, no que se refere aos métodos empregados e aos resultados obtidos, podem ser resumidas conforme segue.

\section{Com relação aos métodos empregados}

O método do déficit total de água, por representar de forma mais eficiente o balanço entre perdas e ganhos de água entre os períodos de tempo em análise, permitindo a determinação das alterações na disponibilidade hídrica em cada unidade de tempo, se mostrou mais indicado para o cálculo das vazões indisponibilizadas.

As curvas de permanência, por representarem as características hídricas de longo prazo das bacias e não indicarem a sequência temporal de ocorrência das vazões, não permitem a identificação das condições de disponibilidade hídrica em cada unidade de tempo, conferindo a esse método, no que se refere ao atendimento do objetivo proposto, menor eficiência.

O método do déficit total de água penaliza sobremaneira as usinas hidrelétricas, ao desconsiderar sempre, no cálculo dos déficits, os armazenamentos que ocorrem no período. $\mathrm{O}$ cenário 1 gera vazões indisponibilizadas altas, pois tem como premissa a hipótese pouco provável na prática de que toda a água disponível pode ser usada pelos usuários. O cenário 2 considera a situação mais próxima do uso da água nas bacias hidrográficas, na qual a vazão disponível para cada usuário é aquela com determinada probabilidade de ocorrência. Em consequência, as vazões indisponibilizadas resultantes são bastante coerentes e inferiores às obtidas no cenário 1 .

\section{Com relação aos resultados obtidos}

As vazões indisponibilizadas calculadas pelos métodos utilizados apresentam diferenças entre si, em função da formulação intrínseca de cada método. Porém essas vazões representam de forma muito 
apropriada os impactos sobre a disponibilidade hídrica, em contraposição ao método empregado atualmente para a cobrança para as usinas hidrelétricas.

As vazões indisponibilizadas obtidas pelo método do déficit total de água no cenário 1 são sempre superiores às respectivas vazões obtidas no cenário 2 , em função das vazões consideradas em suas formulações (vazão natural no cenário 1 e vazão $Q_{95 \%}$ no cenário 2). Da mesma forma, as vazões indisponibilizadas do cenário 1 são também sempre superiores às vazões indisponibilizadas obtidas pelo método da curva de permanência. Ou seja, as maiores vazões indisponibilizadas foram obtidas pelo método do déficit total de água cenário 1, visto que esse método, além de desconsiderar os armazenamentos, disponibiliza toda a água aos usuários.

Para as usinas estudadas, à exceção de Foz do Areia, foram identificadas vazões indisponibilizadas nulas na maioria dos anos analisados, em particular quando se empregam o método da curva de permanência e o método do déficit total de água cenário 2.

Cabe esclarecer que os métodos aqui apresentados foram igualmente aplicados às usinas Jurumirim, Chavantes, Salto Grande, Capivara, Taquaruçu e Rosana, localizadas no rio Paranapanema. Os resultados obtidos e as conclusões acerca dos métodos utilizados são os mesmos, podendo ser consultados em Müller (2009).

Enfim, cabe a observação de que a cobrança definida pela Lei $n^{\circ}$ 9.433/97 reflete apenas a ótica dos recursos hídricos e não considera outros impactos gerados pelas usinas hidrelétricas, como o lucro cessante da área ocupada pelo reservatório ou eventuais alterações no ecossistema local. A metodologia desenvolvida nesta pesquisa, em acordo com as diretrizes da lei, considera apenas os impactos sobre a disponibilidade hídrica e desvincula a cobrança pelo uso da água de pagamentos devidos a outros possíveis impactos. Pretende-se, com a metodologia de cobrança proposta, atender ao objetivo de contribuir na melhoria da disponibilidade hídrica nas bacias. Outros objetivos, como a conservação do meio ambiente e a distribuição de renda, devem ser objeto de outros instrumentos legais.

Finalmente, reconhecem-se as dificuldades, ou mesmo inconveniências, de se adotarem, no curto prazo, novas regras para a cobrança pelo uso da água para o setor hidrelétrico, especialmente devido ao risco do SINGREH sofrer um forte impacto no caso de mudanças significativas na arrecadação proveniente desse setor. No entanto, é notório que, no médio prazo, apesar das dificuldades políticas associadas, a cobrança pelo uso da água para o setor hidrelétrico deverá ser reavaliada, como forma de garantir a manutenção da credibilidade da PNRH e a continuidade da implementação do SINGREH.

\section{REFERÊNCIAS}

AGÊNCIA NACIONAL DE ENERGIA ELÉTRICA (ANEEL). Disponível em: <http://www.gov.br>. Acesso em: 22/04/2007.

BRASIL. Ministério de Meio Ambiente. Secretaria de Recursos Hídricos. Recursos hídricos: conjunto de normas legais. 3. ed. Brasília, 2004. 243 p.

CARRERA-FERNANDEZ, J.; GARRIDO, R. J. Economia dos recursos hídricos. Salvador: Edufba, 2002. $457 \mathrm{p}$.

CORDEIRO NETTO, O. de M. Senado Federal. Comissão de Serviços de Infraestrutura. Ementa: submete à apreciação do Senado Federal a indicação do Senhor Oscar de Moraes Cordeiro Netto para exercer o cargo de Diretor da Agência Nacional de Águas (ANA), na vaga da Senhora Dilma Seli Pena Pereira. [Brasília]. Reunião Extraordinária, Item- no 01 - Mensagem no 78 de 24 de agosto de 2004.

GOMIDE, F. L. S. Dimensionamento de sistemas de reservatórios: introdução à teoria estocástica dos reservatórios. In: Curso de Engenharia Hidrológica. São Paulo: EPUSP; DAEE; ABRH, 1983. v. 2.

INSTITUTO DE TECNOLOGIA PARA O DESENVOLVIMENTO (LACTEC). Projeto HG-193. Estudos de consistência e reconstituição de séries de vazões naturais na bacia do Rio Iguaçu: relatório final. Curitiba: LACTEC; CEHPAR, 2003. 156 p. Relatório técnico.

KELMAN, J. Outorga e cobrança de recursos hídricos. In: THAME, A. C. de M. (Org.). A cobrança pelo uso da água. São Paulo: IQUAL, 2000. p. 93 - 113. 
LINSLEY, R. K.; FRANZINI, J. B. Engenharia de recursos hídricos. São Paulo: McGraw-Hill do Brasil, 1978. 798 p.

MÜLLER I. I. Proposta de uma metodologia de cobrança pelo uso da água para o setor hidrelétrico: avaliação das vazões indisponibilizadas por usinas hidrelétricas em bacias hidrográficas. 281 p. Tese (Doutorado em Engenharia Florestal) - Universidade Federal do Paraná, Curitiba, 2009.

OPERADOR NACIONAL DO SISTEMA ELÉTRICO (ONS). Submódulo 20.1: definições e glossário, 2002. 55 p. Disponível em: <http://www.ons.org.br>. Acesso em: 22/04/2007.

Revisão das séries de vazões naturais nas principais bacias do SIN: relatório executivo. Brasília, 2005. 126 p.

PEREIRA, J. dos S. A cobrança pelo uso da água como instrumento de gestão dos recursos hídricos: da experiência francesa à prática brasileira. 205 p. Tese (Doutorado em Engenharia de Recursos Hídricos e Saneamento Ambiental) - Universidade Federal do Rio Grande do Sul, Porto Alegre, 2002.

PINTO, N. L. de S.; HOLTZ, A. C. T.; MARTINS, J. A.; GOMIDE, F. L. S. Hidrologia básica. São Paulo: Edgard Blücher, 1976. 278 p.

SUGAI, M. R. V. B. Compensação financeira, royalites e o pagamento pelo uso de recursos hídricos no caso de aproveitamentos hidrelétricos. In: SEMINÁRIO PERSPECTIVAS PARA A COBRANÇA PELO USO DOS RECURSOS HÍDRICOS NO BRASIL, 2008, Rio de Janeiro. Anais... Rio de Janeiro: CNRH; CTCOB, 2008. 6 p.

TAVARES, V. E.; RIBEIRO-RIOS, M. M.; LANNA, A. E. Valoração monetária de bens e serviços ambientais: revisão do estado da arte sob a ótica da gestão das águas. Revista Brasileira de Recursos Hídricos, Porto Alegre, v. 4, n. 3, p. 97 - 116, 1999. 
